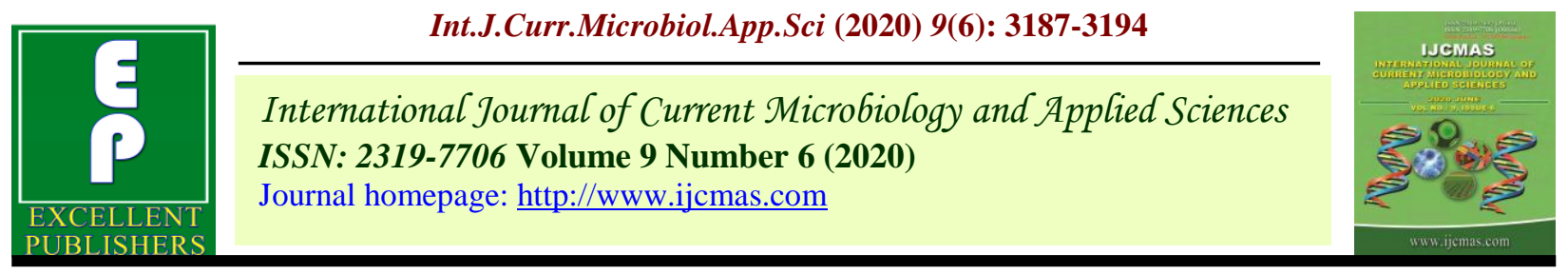

Original Research Article

https://doi.org/10.20546/ijcmas.2020.906.381

\title{
Performance Evaluation of Semi-automatic Coconut De-husking Machine for West Coast Tall Variety of Coconut
}

\author{
M.M. Deo ${ }^{1 *}$, A.C. Mathew ${ }^{2}$, M.R. Manikantan ${ }^{2}$ and K.B. Hebbar ${ }^{2}$ \\ ${ }^{1}$ Division of Crop Production, ICAR-IIPR, Kanpur-208 024 \\ ${ }^{2}$ Division of Physiology, Biochemistry \& Post Harvest Technology, \\ ICAR-Central Plantation Crops Research Institute, Kasaragod, Kerala-671 124, India \\ *Corresponding author
}

\begin{abstract}
A B S T R A C T
Keywords

Coconut, WCT, Dehusking capacity,

De-husking

efficiency

Article Info

Accepted:

21 May 2020

Available Online:

10 June 2020

A semi-automatic coconut de-husker developed at ICAR-CPCRI, Kasaragod, Kerala was tested for its performances for three sizes of West Coast Tall (WCT) coconut variety based on their circumference i.e. Large $(50-55 \mathrm{~cm})$, medium $(45-50 \mathrm{~cm})$ and small $(40-45 \mathrm{~cm})$. De-husking capacity of large, medium and small size coconuts were observed as 193 nuts/h, 155 nuts/h and 94 nuts/h with de-husking efficiency of $98 \%, 97 \%$ and $35 \%$ respectively. There was significant difference in de-husking capacity of all three sizes of nuts. In case of de-husking efficiency, large and medium size nut exhibited insignificant difference but small size revealed significantly lower efficiency.
\end{abstract}

\section{Introduction}

Coconut (Cocos nucifera L.) is known as the 'Kalpa Vriksha' (Tree of Paradise) in India, as its every part is utilized for one or other purposes. It provides food in form of copra, drink in the form of tender-nut water, fibre for cushioning, wood is used as fuel and also in making shelter homes, it also gives us coconut oil, coconut sugar, coconut chips, virgin coconut oil, coco pit besides many other uses. It is grown in different countries of the world covering around 93 countries. Major countries are India, Indonesia,
Philippines and Sri Lanka which shared together 77 and 79 percent of the world's coconut area and world's coconut production, respectively. India is the second largest producer of coconut in the world. It had a production of 16412.6 thousand million tonnes of coconut in the area of 20.96 lakh hectares with the productivity of $7.8 \mathrm{MT} / \mathrm{ha}$ for the year of 2017-18 (Anonymous, 2018) (Fig.1). Coconut crop is grown in different states of India. Kerala, Karnataka and Tamil $\mathrm{Nadu}$ are major coconut producing states, which together contributes around 84.27 percent of total coconut area and 87.17 
percent of total coconut production in the country in 2017-18 (Anonymous, 2018).

Kerala is the largest producer of coconut in the country with a production of 5.8 lakh million tonnes in the area of 8.07 lakh hectares followed by Karnataka and Tamil Nadu with a production of 4.3 lakh, 4.15 lakh million tonnes in the area of 5.18 and 4.41 lakh hectares respectively in 2017-18 (Anonymous, 2018). Coconut de-husking is the first postharvest operation in coconut processing industry, but it is regarded as the most time consuming, cumbersome and difficult operation to perform and involves much human drudgery. De-husking with traditional hand tools like sickle or a spike depends on the skill of worker and involves training. Now a days, there is a shortage of such skilled workers. Keeping this in mind, a semi-automatic coconut de-husking machine was developed at ICAR-CPCRI, Kasaragod and evaluated for different sizes of WCT (West Coast Tall) variety coconut.

\section{Review of literature}

Coconut de-husking is first operation in coconut processing operation and required for developing many coconut products. Researchers have attempted to develop different types of coconut de-husking machines, few of them are mentioned here:

Kwangwaropas (1992) evaluated the performance of hydraulically operated coconut dehusking machine consisted of a 1.5 $\mathrm{kW} 220$ volts electric motor to drive hydraulic pump. Two person could operate this machine and average dehusking time was 10-12 seconds/coconut. The total cost of operation was found as Rs. 1.8/coconut which was half of the price of the convectional method of dehusking.

Owolarate et al., (2008) developed second class lever mechanism type tool for aiding manual dehusking of coconut. Three types of tools were tested to dehusk the Nigerian tall coconut variety having sphericity 75-81 per cent. A female worker could dehusk with a machete, a vertical tool and the new dehusking lever with an average dehusking capacity of 35, 12 and 47 nuts per hours respectively.

Gajakos et al., (2008) developed a power operated coconut dehusker which was operated on a 3-phase, $5 \mathrm{hp}$ electric motor. Dehusking unit of dehusker consisted of two cylinders viz. dehusking cylinder and idle cylinder. Husk was removed by triangular shaped teeth mounted on dehusking cylinder, which penetrated into the husk and pulled it away from the coconut. Performance parameters like average time requirement, dehusking capacity, dehusking efficiency, damage percentage, average power requirement were calculated for coconut dehusking. For dehusking of single coconut average time required was found to be 16.56 seconds. Dehusking efficiency, dehusking capacity, damage percentage and average power consumption were observed as $82.0 \%$, 200-225 nuts/h, $18.0 \%$ and $4.43 \mathrm{hp}$ respectively. Single person could operate the coconut dehusker.

Ghosal and Sarkar (2013) studied and evaluated the performance and ergonomics of a power operated coconut de-husker. Different performance parameters namely; de-husking efficiency, de-husking capacity and ergonomical considerations like heart rate, oxygen consumption rate etc. were measured during testing. Dehusking capacity and dehusking efficiency were observed as 300 nuts/h and $92 \%$ respectively. The machine cost for de-husking of single nut was found to be Rs. 0.10 per nut.

Ghosal et al., (2014) developed and evaluated the performance of a power operated coconut dehusking machine for three varieties of 
coconut, i.e. Sakhigopal, Guamal and Hazari. The highest dehusking capacity of 330 nuts/h was observed for Sakhigopal variety followed by Guamal and Hazari (324 nuts/h) varieties. However, the dehusking efficiency of observed to be highest in case of Sakhigopal variety $(92.45 \%)$, but, there was no significant difference in all the three varieties i.e. Sakhigopal, Guamal and Hazari.

Patil et al., (2015) developed a low cost, medium speed coconut dehusker at Dr. Balasaheb Sawant Konkan Krishi Vidyapeeth, Dapoli. It consisted of main frame, electric motor, gear box, cam and follower, lifter, holding mechanism and splitting mechanism etc. The performance of dehusker was evaluated on the basis of dehusking time, output capacity, dehusking efficiency and operating cost etc. The average dehusking time required to dehusk one coconut was 30.6 $\mathrm{s}$ and output capacity was 118 nuts/h, which was 40 per cent higher than the manual dehusker. The average dehusking efficiency of developed power operated dehusker was 96.62 per cent. The machine could dehusk any shape and sizes of coconut without nut breakage.

Varghese et al., (2017) studied the physical and mechanical properties of local varieties of Indian coconuts to optimize the effort and productivity relationship. A sample of 70 coconuts were taken from coconut palms in Kerala, India, and divided into two groups of 35 each, dry and green coconuts. Its physical properties (size, weight, husk thickness, moisture content, and shell diameter) and mechanical properties (husk-separating force and shell-breaking force) were measured and the relationship between them was investigated. The results showed that high dependence of mechanical properties existed on the physical properties of the coconut. Pandiselvam et al., (2018) found the physical and engineering properties of different varieties of coconut, namely Malayan Yellow Dwarf, Malayan Orange Dwarf, Kera Shankara, Chowghat Orange Dwarf, and Chowghat Green Dwarf. A sample of 40 coconuts of each variety, were taken for study and divided into two groups (20 dry and 20 green coconuts), and measurement was done. Different varieties of coconut based on maturity levels showed diversity in size, density, husk thickness, husk weight, shell thickness, shell weight, and kernel thickness.

\section{Materials and Methods}

A semi-automatic coconut de-husking machine was developed at ICAR-CPCRI, Kasaragod and evaluated for different sizes of WCT (West Coast Tall) variety coconut (Fig. 2). Specification of the developed dehusker is mentioned in Table 1. There are two dehusking units in this machine i.e. primary dehusking and secondary de-husking unit (Fig. 3) and are used for primary de-husking and tail fibre removing respectively. For primary de-husking, there are two rollers with pins on their surface and rotates at $35 \mathrm{rpm}$ each. A leather conveyer belt is provided to hold and convey the coconuts of different sizes, but minimum space is fixed for easy feeding of coconuts. For tail fibre removing, two blade type rollers rotating at $28 \mathrm{rpm}$ and one helical type roller rotating at $56 \mathrm{rpm}$ is provided.

Developed de-husker was tested for West Coast Tall (WCT) variety of coconut for its performance. Performance was measured in terms of de-husking capacity and de-husking efficiency. Initially, Length, breadth, thickness of freshly harvested mature WCT variety of coconuts were measured with the help of digital Vernier calliper of least count of $0.01 \mathrm{~mm}$. Smaller and longer circumferences were measured with the help of a wire then put on a measuring scale of least count of $0.1 \mathrm{~cm}$ to get the exact dimension (Fig. 4). Based on the small 
circumferential dimensions, coconuts were divided into three categories, namely small $(40-45 \mathrm{~cm})$, medium $(45-50 \mathrm{~cm})$ and large (50-55 cm) (Fig. 5).

Each of three sizes WCT variety coconuts 30 in numbers were taken in three replications and time taken were noted down for dehusking of these coconuts, when continuously fed by a lady in de-husker inlet and de-husked and un-husked coconuts were also counted at outlet point (Fig.6. and Fig. 7.). De-husking capacity and de-husking efficiencies were determined as follows (Ghosal et al., 2014):

Dehusking capacity, $\frac{\text { nuts }}{h}=\frac{\text { Total no,of nut dehusked }}{\text { time taken( }(h)}$
Dehusking efficiency $(\%)=\frac{\text { weight of husk obtained after dehusking }}{\text { weight of total husk present in coconut }} \times 100$

\section{Results and Discussion}

Physical dimensions of freshly harvested thirty WCT variety of coconuts were measured in three replications each and were found as given in Table 2. Length, breadth, and thickness varied from 17.26 \pm 1.21 , $13.08 \pm 0.83$, and $12.47 \pm 0.81 \mathrm{~cm}$ for small size coconuts to $22.22 \pm 1.19,16.56 \pm 0.73$, and $15.62 \pm 0.70 \mathrm{~cm}$ for larger size of coconuts, respectively. Whereas, small and large circumference varied from $42.39 \pm 2.66$ to $53.51 \pm 2.30 \mathrm{~cm}$ and $49.36 \pm 2.86$ to $62.32 \pm 3.22$ $\mathrm{cm}$ for small size nuts and large size nuts, respectively.

Table.1 Specifications of coconut de-husker

\begin{tabular}{|l|l|}
\hline Particulars & Dimensions \\
\hline Size & $140 \times 100 \times 85 \mathrm{~cm}$ \\
\hline Prime mover & 2 HP Motor \\
\hline Feeding unit, size & $35 \times 30 \mathrm{~cm}$ \\
\hline Roller (Two) spike nos. & 19 \\
\hline Spiked roller, rpm (Two nos.) & 35 \\
\hline Blade type rollers, rpm (Two nos.) & 28 \\
\hline One helical type roller, rpm & 56 \\
\hline Helical type roller, length & $75 \mathrm{~cm}$ \\
\hline
\end{tabular}

Table.2 Physical dimensions of WCT variety of coconuts

\begin{tabular}{|c|c|c|c|c|c|}
\hline & $\begin{array}{c}\mathrm{L} \\
(\mathbf{c m})\end{array}$ & $\begin{array}{c}\text { b } \\
(\mathbf{c m})\end{array}$ & $\begin{array}{c}\mathbf{t} \\
(\mathbf{c m})\end{array}$ & $\begin{array}{c}\text { Small } \\
\text { circumference } \\
(\mathbf{c m})\end{array}$ & $\begin{array}{c}\text { Large } \\
\text { circumference } \\
(\mathrm{cm})\end{array}$ \\
\hline Small size nuts & $17.26 \pm 1.21$ & $13.08 \pm 0.83$ & $12.47 \pm 0.81$ & $42.39 \pm 2.66$ & $49.36 \pm 2.86$ \\
\hline $\begin{array}{l}\text { Medium } \\
\text { size nuts }\end{array}$ & $19.63 \pm 1.33$ & $14.91 \pm 0.65$ & $14.21 \pm 0.82$ & $48.86 \pm 2.03$ & $56.16 \pm 2.50$ \\
\hline Large size nuts & $22.22 \pm 1.19$ & $16.56 \pm 0.73$ & $15.62 \pm 0.70$ & $53.51 \pm 2.30$ & $62.32 \pm 3.22$ \\
\hline
\end{tabular}


Table.3 Analysis of Variance (ANOVA) for de-husking capacity

\begin{tabular}{|l|c|c|c|c|c|}
\hline Source & $\begin{array}{c}\text { Degree of } \\
\text { Freedom }\end{array}$ & $\begin{array}{c}\text { Sum of } \\
\text { Squares }\end{array}$ & $\begin{array}{c}\text { Mean } \\
\text { Squares }\end{array}$ & F-value & Probability \\
\hline Total & 8 & 15116.89 & 1889.61 & & \\
\hline Replication & 2 & 149.56 & 74.78 & & \\
\hline Treatment & 2 & 14874.89 & 7437.44 & 321.81 & $0.000 * *$ \\
\hline Error & 4 & 92.44 & 23.11 & & \\
\hline
\end{tabular}

$\mathrm{SEd}=3.92, \mathrm{CD}(.05)=10.89, \mathrm{CD}(.01)=18.07, \mathrm{CV} \%=3.27$

Table.4 Analysis of Variance (ANOVA) for dehusking efficiency

\begin{tabular}{|l|c|c|c|c|c|}
\hline Source & $\begin{array}{c}\text { Degree of } \\
\text { Freedom }\end{array}$ & $\begin{array}{c}\text { Sum of } \\
\text { Squares }\end{array}$ & $\begin{array}{c}\text { Mean } \\
\text { Squares }\end{array}$ & F-value & Probability \\
\hline Total & 8 & 7877.56 & 984.69 & & \\
\hline Replication & 2 & 6.89 & 3.44 & & \\
\hline Treatment & 2 & 7856.89 & 3928.44 & 1140.52 & $0.000 * *$ \\
\hline Error & 4 & 13.78 & 3.44 & & \\
\hline
\end{tabular}

$\mathrm{SEd}=1.51, \mathrm{CD}(.05)=4.21, \mathrm{CD}(.01)=6.98, \mathrm{CV} \%=2.42$

Fig.1 Area and production of coconut in India



Fig.2 ICAR-CPCRI developed coconut de-husker

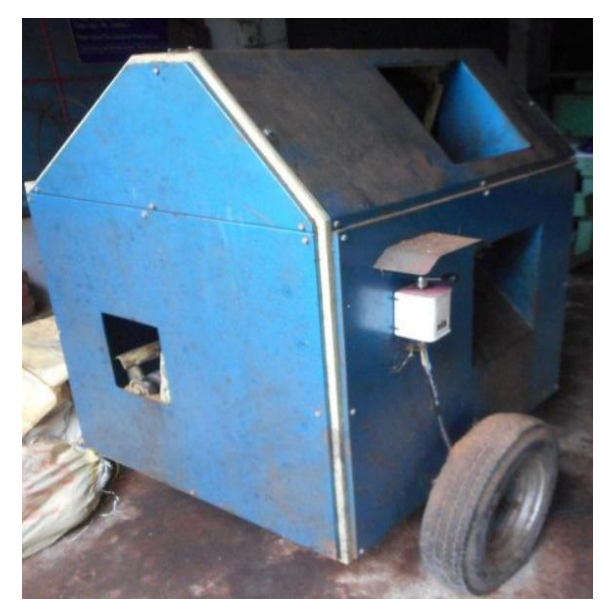


Fig.3 De-husking units in coconut de-husker

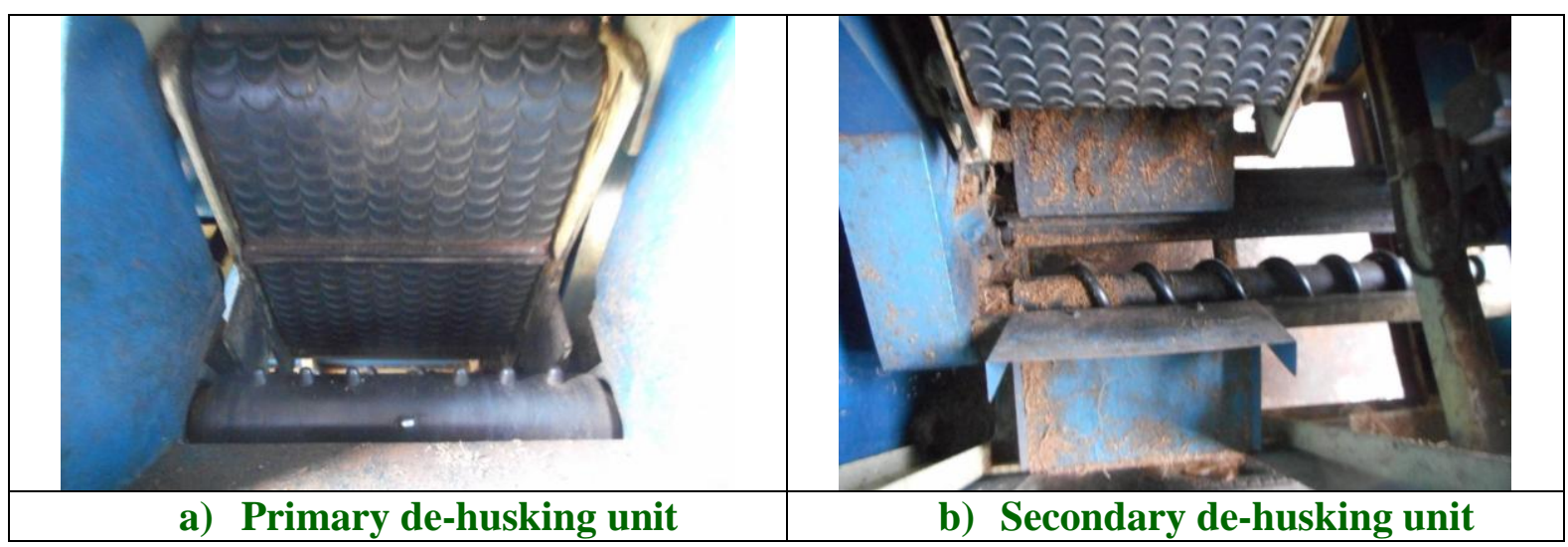

Fig.4 Measurement of dimensions of WCT variety of coconut

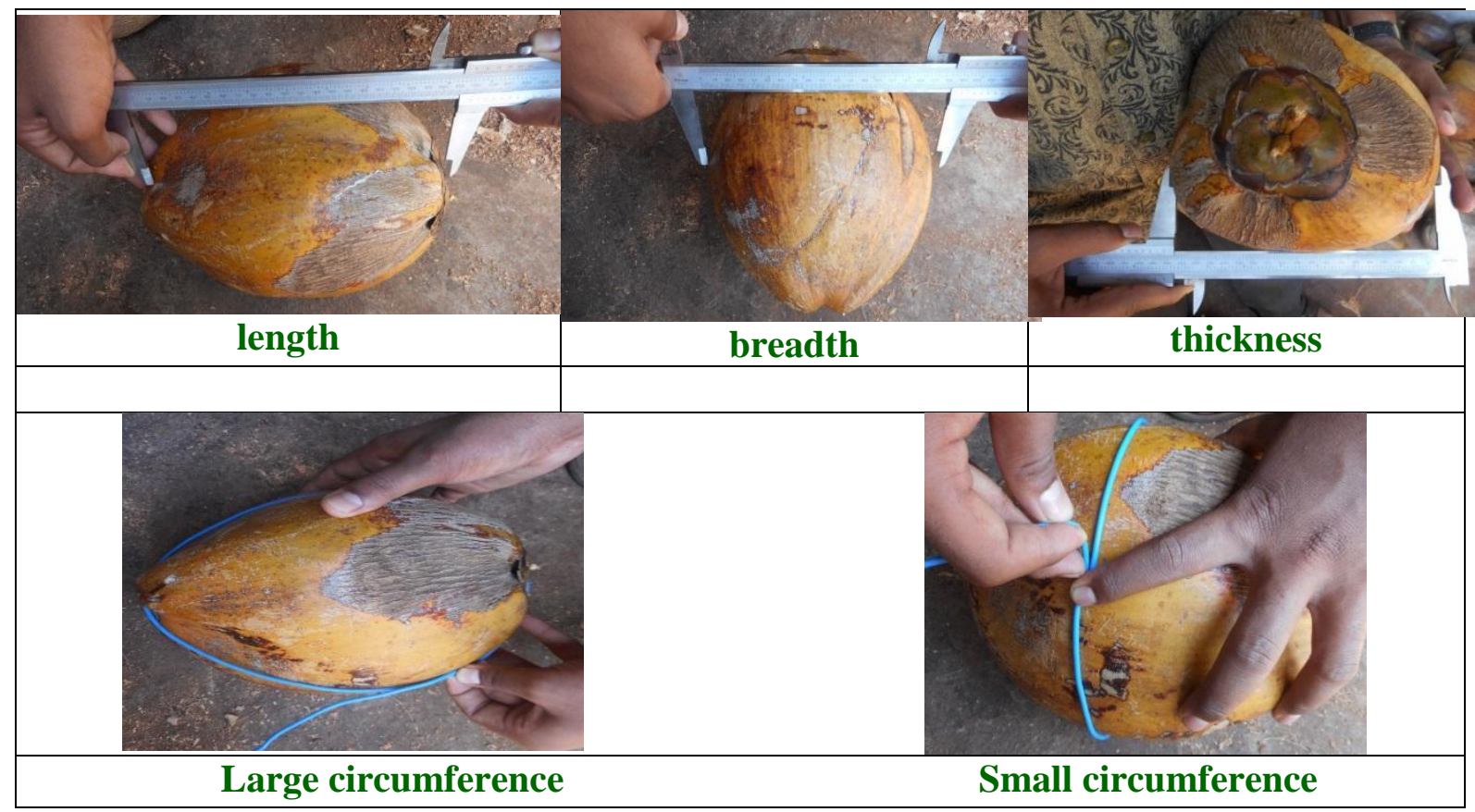

Fig.5 Different sizes of WCT variety of coconuts

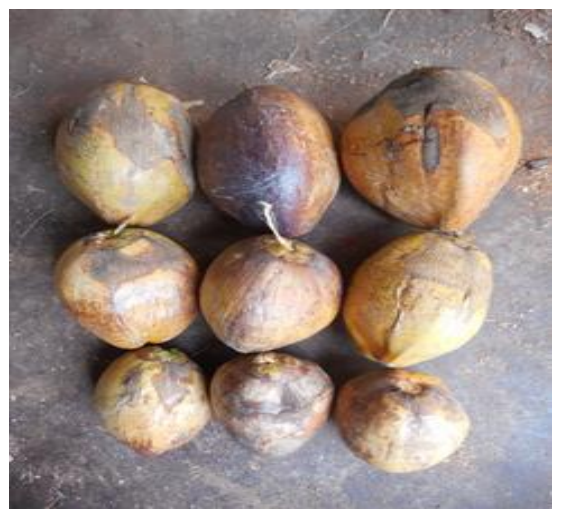




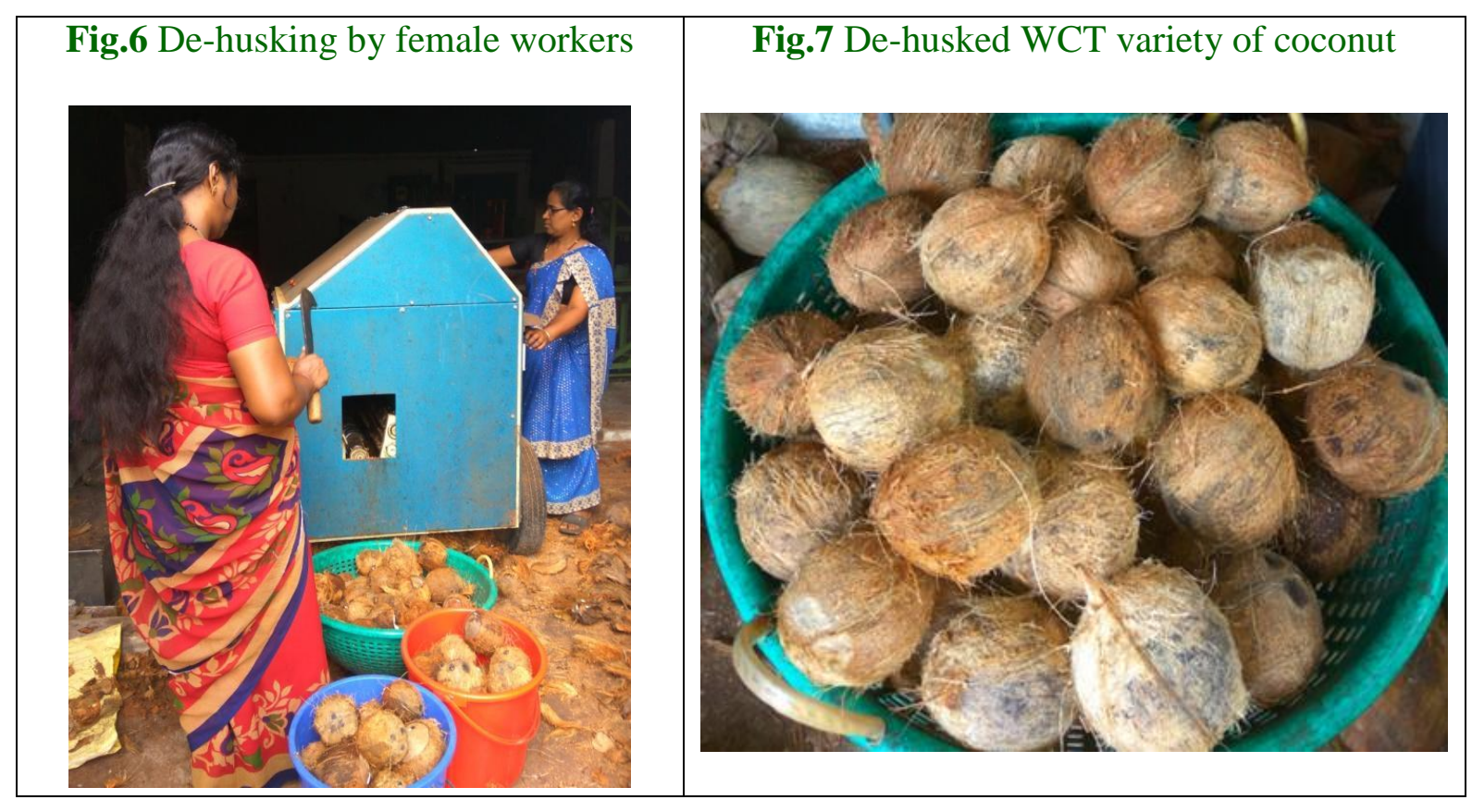

Fig.8 De-husking capacity of different sizes of WCT variety of coconut

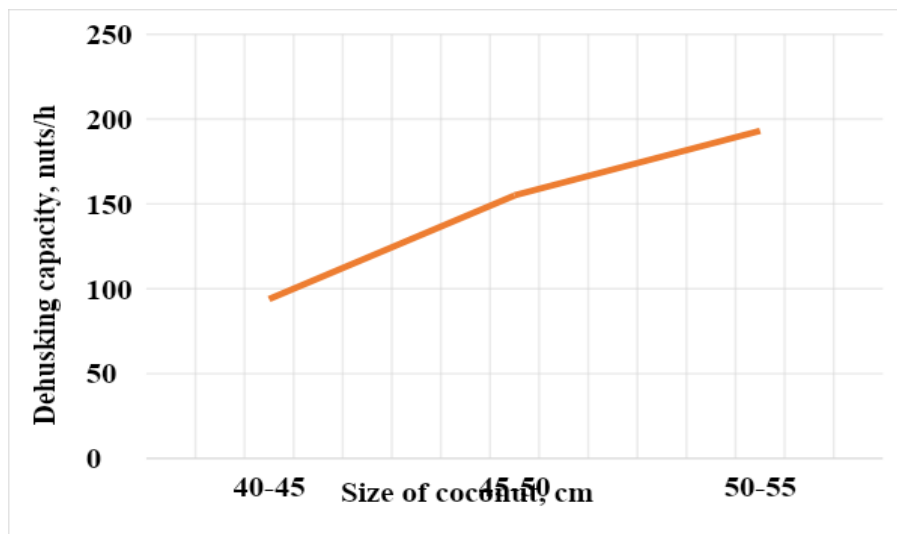

Fig.9 De-husking efficiency (\%) of different sizes of WCT variety of coconut

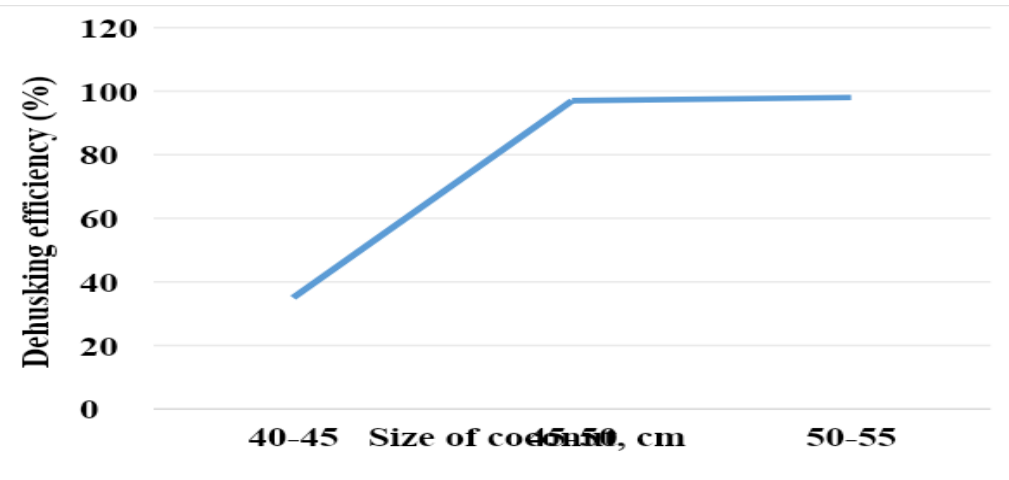




\section{De-husking capacity}

De-husking capacity of large $(50-55 \mathrm{~cm})$, medium $(45-50 \mathrm{~cm})$ and small size $(40-45$ $\mathrm{cm})$ coconuts were observed as 193 nuts $/ \mathrm{h}$, 155 nuts/h and 94 nuts/h respectively as mentioned in Fig. 8. Analysis of Variance (ANOVA) showed that there was significant difference in de-husking capacities of different sizes of WCT variety of coconuts (Table 3.).

\section{De-husking efficiency}

De-husking efficiencies of large $(50-55 \mathrm{~cm})$, medium $(45-50 \mathrm{~cm})$ and small size $(40-45$ $\mathrm{cm})$ coconuts were observed $98 \%, 97 \%$ and $35 \%$ respectively (Fig. 9). Analysis of Variance (ANOVA) for de-husking efficiency showed that large and medium size WCT variety coconuts exhibited insignificant difference but small size revealed significantly lower efficiency (Table 4.).

In conclusions, de-husking capacity of large, medium and small size coconuts were observed as 193 nuts/h, 155 nuts/h and 94 nuts/h with de-husking efficiency of $98 \%$, 97\% and $35 \%$ respectively. There was significant difference in de-husking capacity of all three sizes of nuts. In case of dehusking efficiency, large and medium size nut exhibited insignificant difference but small size revealed significantly lower efficiency.

\section{References}

Anonymous.2018. Agriculture statistics at a glance 2018, Ministry of Agriculture \&
Farmers Welfare, Government of India, pp502.

Gajakos A V; Nalawade S M; Aware V V; Patil S B; Thakur B B. 2008. Development of power operated coconut dehusker. Agriculture Update, 3(1): 167-170.

Ghosal M K; Mishra M; Sutar N C.2014. Development and performance evaluation of a power operated coconut dehusker. Agricultural Engineering Today, 38(1):1-5.

Ghosal M K; Sarkar B. 2013. Performance and ergonomical study of a power operated coconut dehusker. Asian journal of horticulture, 8 (2): 482-486.

Kwangwaropas, M. 1992. Design manufacturing and testing of the hydraulically operated coconut dehusking machine. Kesetsart journal, 25: 219-233.

Owolarate, O. K.; Badmus, O. A. and Adeyemi, N. A. 2008. Development of coconut dehuaking lever. Journal of food science and technology, (45)3:279-281.

Pandiselvam, R., Manikantan, M. R., Kothakota, A., Rajesh, G. K., Beegum, S., Ramesh, S. V., Hebbar, K. B. 2018. Engineering properties of five varieties of coconuts (Cocos nucifera $\mathrm{L}$.) for efficient husk separation. Journal of Natural Fibers, 1-9.

Patil S R; Shahare P U; Aware V V; Shirsat N A. 2015. Development of power operated coconut dehusker. Journal of the Indian Society of Coastal Agricultural Research, 33(1): 52-55.

Varghese A; Francis K; Jacob J. (2017). A Study of Physical and Mechanical Properties of the Indian Coconut for Efficient Dehusking. Journal of Natural Fibres, 14(3):390-399.

\section{How to cite this article:}

Deo, M.M., A.C. Mathew, M.R. Manikantan and Hebbar, K.B. 2020. Performance Evaluation of Semi-automatic Coconut De-husking Machine for West Coast Tall Variety of Coconut. Int.J.Curr.Microbiol.App.Sci. 9(06): 3187-3194. doi: https://doi.org/10.20546/ijcmas.2020.906.381 